\title{
Features of gold nanoparticles application for bio- and nanosensors
}

\begin{abstract}
The paper presents short review of the features of gold nanoparticles application for various biosensors and nanosensors. The main specific properties of gold nanoparticles which determine their use in the development of different types of biosensors and nanosensors are discussed in brief.
\end{abstract}

Keywords:gold nanoparticles, biosensors, nanosensors, detection
Volume 4 Issue 2 - 2018

\author{
Liudmyla Rieznichenko',2 \\ 'Department of Colloidal Technology of Natural Systems, FD \\ Ovcharenko Institute of Biocolloidal Chemistry, Ukraine \\ ${ }^{2}$ Institute of Veterinary Medicine, Ukraine
}

\begin{abstract}
Correspondence: Liudmyla Rieznichenko, FD Ovcharenko Institute of Biocolloidal Chemistry, Vernadskogo Av, 42, 03142 Kyiv, Ukraine, Tel +380(44)424-19-19, Fax +380(44)424-8078, Email Irieznichenko@gmail.com
\end{abstract}

Received: February 19, 2018 | Published: March 05, 2018
Abbreviations: AuNP, gold nanoparticles; LSPR, localized surface plasmon resonance; SERS, surface enhanced Raman scattering

\section{Introduction}

Due to the complex of unique chemical, physical and biological properties nanomaterials are actively used today in technologies of various sensors development. ${ }^{1-3}$ The application of nanomaterials gives opportunity to provide revolutionary changes in sensitivity, specificity and rapidity of detection as well multiplexing capability, simple operation, miniaturization and low cost of such devices. Among nanostructures fullerenes, single walled and multiwalled carbon nanotubes, magnetic nanoparticles, modified silicon nanowires, dendrimers, quantum dots and others have found their use in the practice of bio-and nanosensors development, but only gold nanoparticles (AuNP) can be marked as the most used and widespread. $^{4-7}$

\section{Discussion}

Besides the common properties typical for nanomaterials, the main specific characteristics of gold nanostructures such as quite simple methods for controlled synthesis of particles with certain size and shape (including spherical nanoparticles, nanorods, nawires, nanoshells, nanodisks, nanocubes, nanotriangles, nanooctahedrons etc.), stability for a long period of time, easy surface functionalization, biocompatibility, unique optical properties and high catalytic activity provide the successful use of gold nanoparticles in the development of various bio-and nanosensors. ${ }^{7-11}$ The specific characteristics mentioned above determine the main features of AuNP use in the development of different types of biosensors and nanosensors for detection of various samples including inorganic and organic pollutants,,${ }^{4,12-14}$ toxins, ${ }^{15,16}$ pathogens, ${ }^{5,17}$ biomolecules, ${ }^{6,18-20}$ enzyme activity, ${ }^{10,21}$ as well as diagnostics of different diseases, ${ }^{22,23}$ etc. Thus, unique size-dependent optical properties of AuNP in combination with capabilities to surface functionalization define their effective use in the development of various LSPR-based, SERS-based and colorimetric nano- and biosensors. ${ }^{24,25}$ The use of gold nanoparticles in such sensors gives opportunity to amplify the signal and as result to enhance sensitivity of the device. The possibility of easy immobilization of antibodies on the nanoparticles surface determines the AuNP effective use in the development of nanoimmunosensors. ${ }^{26}$ Due to the own specific features AuNP are also found their effective application like ink in the inkjet-printing technologies under the development of novel class of miniature, high sensitive and cost-effective sensors. ${ }^{27}$

\section{Conclusion}

Therefore, in compare with other nanomaterials AuNP due to the combination of unique features occupy the leading position in their usefulness for development of new biosensors and nanosensors with high sensitivity, specificity, rapidity of detection and other key necessary properties.

\section{Acknowledgements}

None.

\section{Conflict of interest}

None.

\section{References}

1. Kurbanoglu S, Ozkan S. Electrochemical carbon based nanosensors: a promising tool in pharmaceutical and biomedical analysis. $J$ Pharm Biomed Anal. 2018;147:439-457.

2. Suresh S, Mathan P. Recent trends in nanobiosensors and their applications - a review. Rev Adv Mater Sci. 2014;36:62-69. 
3. Lim JW, Ha D, Lee J, et al. Review of micro/nanotechnologies for microbial biosensors. Front Bioeng Biotechnol. 2015;3:61.

4. Zhang M, Cheng F, Gan F. Electrochemical nitrite nanosensor based on Au nanoparticles/graphene nanocomposites. Int J Electrochem Sci. 2015;10:5905-5913.

5. Ali MA, Salah Eldin TA, El Moghazy GM, et al. Detection of E.coli O157:H7 in feed samples using gold nanoparticles sensor. Int J Curr Microbiol App Sci. 2014;3(6):697-708.

6. Gu S, Ma K, Kong J, et al. Functionalized polyethyleneimine-gold nanoparticles-porphyrin nanocomposite for electrochemical glucose biosensing. Int J Electrochem Sci. 2017;12:5092-5103.

7. Yu X, Jiao Y, Chai Q. Applications of Gold Nanoparticles in Biosensors. Nano LIFE. 2016;6(2):11.

8. Chai F, Wang $\mathrm{C}$, Wang $\mathrm{T}$, et al. Colorimetric detection of $\mathrm{Pb} 2+$ using glutathione functionalized gold nanoparticles. ACS Appl Mater Interfaces. 2010;2(5):1466-1470.

9. Mocan T, Matea CT, Pop T, et al. Development of nanoparticle-based optical sensors for pathogenic bacterial detection. J Nanobiotechnol. 2017;15(1):25.

10. Chuang YC, Huang WT, Chiang PH, et al. Aqueous zymography screening of matrix metalloproteinase activity and inhibition based on colorimetric gold nanoparticles. Biosens Bioelectronics. 2012;32(1):24 31 .

11. Wang L, Yang P, Li Y, et al. A flow injection chemiluminescence method for the determination of fluoroquinolone derivative using the reaction of luminol and hydrogen peroxide catalyzed by gold nanoparticles. Talanta. 2007;72(3):1066-1072.

12. Azzam EMS, Abd El-aal AA, Shekhah O, et al. Fabrication of SPR nanosensor using gold nanoparticles and self-assembled monolayer technique for detection of $\mathrm{Cu}^{2+}$ in an aqueous solution. Journal of Dispersion Science and Technology. 2014;35(5):717-724.

13. Barahona F, Bardliving CL, Phifer A, et al. An aptasensor based on polymer-gold nanoparticle composite microspheres for the detection of malathion using surface-enhanced Raman spectroscopy. Industrial Biotechnology. 2013;9(1):42-50.

14. Xiao N, Yu C. Rapid-response and highly sensitive noncross-linking colorimetric nitrite sensor using 4-aminothiophenol modified gold nanorods. Anal Chem. 2010;82:3659-3663.

15. Shim WBO, Kim KY, Chung DH. Development and validation of a gold nanoparticle immunochromatographic assay (ICG) for the detection of zearalenone. J Agric Food Chem. 2009;57(10):40354041 .

16. Sertova NM. Application of nanotechnology in detection of mycotoxins and in agricultural sector. Journal of Central European Agriculture. 2015;16(2):117-130.

17. Verma MS, Rogowski JL, Jones L, et al. Colorimetric biosensing of pathogens using gold nanoparticles. Biotechnol Adv. 2015; 33(6 Pt 1):666-680.

18. Zulkifli ZA, Ridhuan NS, Nor NM, et al. The effect of gold nanoparticles modified electrode on the glucose sensing performance. AIP Conference Proceedings. 2017.

19. Deng J, Lu Q, Hou Y, et al. Nanosensor composed of nitrogen-doped carbon dots and gold nanoparticles for highly selective detection of cysteine with multiple signals. Anal Chem. 2015;87(4):2195-2203.

20. Polak P, Zalevsky Z, Shefi O. Gold nanoparticles-based biosensing of sings nucleotide DNA mutations. International Journal of Biological Macromolecules. 2013;59:134-137.

21. Hutter E, Maysinger D. Gold-nanoparticle-based biosensors for detection of enzyme activity. Trends Pharmacol Sci. 2013;34(9):497507.

22. Kumar A, Boruah BM, Liang XJ. Gold Nanoparticles: Promising Nanomaterials for the Diagnosis of Cancer and HIV/AIDS. Journal of Nanomaterials. 2011. 17p.

23. Lin M, Pei H, Yang F, et al. Applications of Gold Nanoparticles in the Detection and Identification of Infectious Diseases and Biothreats. $A d v$ Mater. 2013;25(25):3490-3496.

24. Hong X, Hall EAH. Contribution of gold nanoparticles to the signal amplification in surface plasmon resonance. Analyst. 2012;137(20):4712-4719.

25. Nie L, Liu F, Ma P, et al. Applications of Gold Nanoparticles in Optical Biosensors. J Biomed Nanotechnol. 2014;10(10):2700-2721.

26. Lu D, Lu F, Pang G. A novel tetrahydrocannabinol electrochemical nano immunosensor based on horseradish peroxidase and doublelayer gold nanoparticles. Molecules. 2016;21(10).

27. Jensen GC, Krause CE, Sotzing GA, et al. Inkjet-printed gold nanoparticle electrochemical arrays on plastic. Application to immunodetection of a cancer biomarker protein. Phys Chem Chem Phys. 2011;13(11):4888-4894. 